\title{
Representaciones de los profesores en torno a la didáctica del plurilingüismo. Un proceso de formación
}

\section{Montserrat Fons y Juli Palou}

\section{(2) OpenEdition \\ Journals}

Edición electrónica

URL: http://journals.openedition.org/trema/3242

DOI: $10.4000 /$ trema.3242

ISSN: 2107-0997

Editor

Faculté d'Éducation de l'université de Montpellier

Edición impresa

Fecha de publicación: 1 noviembre 2014

Paginación: 114 - 127

ISSN: 1167-315X

Referencia electrónica

Montserrat Fons et Juli Palou, «Representaciones de los profesores en torno a la didáctica del plurilingüismo. Un proceso de formación », Tréma [En ligne], 42 | 2014, mis en ligne le 16 juin 2015, consulté le 10 décembre 2020. URL : http://journals.openedition.org/trema/3242 ; DOI : https:// doi.org/10.4000/trema.3242

Este documento fue generado automáticamente el 10 diciembre 2020.

Trema 


\title{
Representaciones de los profesores en torno a la didáctica del plurilingüismo. Un proceso de formación
}

\author{
Montserrat Fons y Juli Palou
}

\section{Presentación}

1 El trabajo que presentamos forma parte del proyecto Evolución de las creencias de los profesores de lenguas en aulas multiculturales y plurilingües (ECRELEN) ${ }^{1}$ que lleva a cabo el grupo de investigación Plurilingüismo y Aprendizaje de Lenguas (en adelante, PLURAL) ${ }^{2}$, del Departamento de Didáctica de la Lengua y la Literatura de la Universitat de Barcelona. Este grupo centra su atención en el análisis de la vida mental de los profesores y la relación que tiene ésta con su actuación en el aula (Cambra \& Palou, 2007; Palou \& Fons, 2008).

2 A partir de los trabajos de Woods (1996), miembros del grupo PLURAL (Cambra et al., 2000) definieron un nuevo constructo que incluye las creencias, las representaciones y los saberes (CRS) en forma de sistema. Este constructo, que encierra una gran complejidad, ha sido útil en los sucesivos trabajos del grupo para analizar la vida mental de los docentes y sus modificaciones. De acuerdo con Cambra et al. (2000) en el sistema CRS, las creencias operan como elementos personales poco estructurados, las representaciones como nociones elaboradas y compartidas por un grupo social o una cultura docente y los saberes como opiniones convencionalmente aceptadas. Las relaciones que construye cada docente entre los tres aspectos mencionados constituyen su sistema de CRS.

3 En este artículo analizaremos el CRS de un maestro de educación primaria, al que denominaremos Santi, que imparte la asignatura de lengua extranjera (inglés). Este análisis nos permitirá detectar cómo expresa y conceptualiza un maestro su experiencia profesional en un entorno de una gran heterogeneidad, en lo que se refiere a la presencia 
de distintas lenguas y culturas. Entendemos que este trabajo es imprescindible si se pretenden sentar las bases más adecuadas para llevar a cabo un proceso de formación que tenga como objetivo promover una didáctica del plurilingüismo, en la línea del proyecto de Educación Plurilingüe Intercultural (EPI) impulsado por Consejo de Europa.

Es bien conocido el papel que juega el sistema de CRS en cualquiera de los momentos del ciclo didáctico: planificación, acción y evaluación. En el caso de las lenguas, las representaciones que sostiene cada maestro sobre cuestiones como «qué es una lengua», "qué significa saber una lengua», «la motivación para aprender una lengua» y sobre «cómo se aprenden lenguas» se convierten en elementos decisivos en el momento de establecer criterios didácticos para una EPI en aulas plurilingües.

El sistema de CRS de cada profesor es un filtro que orienta sus decisiones. Siguiendo a Causa (2012) podemos afirmar que el sistema de CRS guarda una gran complicidad con modelos didácticos a los cuales se aferran los profesores, ya que estos ofrecen pistas claras para la actuación. Estos modelos se consideran «Un conjunto de referencias teóricas y prácticas que los enseñantes forjan a partir de la experiencia personal y formativa por impregnación, observación e imitación».

6 Partimos de la premisa que hacer conscientes los modelos de los cuales se parte y abrir espacios donde emerjan de manera clara los CRS que los sustentan es uno de los pasos necesarios para construir nuevas propuestas didácticas. Tomamos, por lo tanto, como puntos de referencia las tesis sobre las relaciones entre el pensamiento y la acción, desarrolladas en las últimas décadas del siglo pasado (Calderhead, 1996; Shavelson \& Stern, 1981; Clark \& Peterson, 1986) y aquellos constructos utilizados para explicar las relaciones entre conocimiento teórico y práctica educativa, ya sea en forma de «teoríasen-acción», de «repertorios» (Schön, 1987), de «modelos mentales» (Rodrigo, 1997), de «representaciones implícitas» (Pozo et al., 2006) o de «artefactos prácticos» (Clarà \& Mauri, 2010).

7 Dentro del campo específico de la didáctica de las lenguas, los estudios de Johnson (1994), Freeman (1996), Meijer, Verloop y Beijard (1999), Moore (2001) y en especial Woods (1996) (véase la revisión de Borg, 2003 \& 2006), han descrito las diferentes teorías implícitas, concepciones, creencias y saberes prácticos de los profesores, que influyen en la toma de decisiones antes o durante las clases, $\mathrm{y}$ han puesto de manifiesto la problemática en torno a la conceptualización de las nociones de «creencias» y de « conocimiento » (véase Borg, 2003 \& Cambra, 2003).

8 Bajo estas premisas presentamos a continuación una breve descripción del diseño de nuestra investigación, para presentar más adelante parte de los resultados.

\section{Participantes}

9 Santi formó parte del grupo de 10 profesores de aulas multiculturales y multilingües, de distintas etapas educativas de la ciudad de Barcelona y su entorno, que participó de manera activa en el proyecto ECRELEN. Los criterios para seleccionar a los profesores participantes en esta investigación fueron tres. En primer lugar, se consideró la experiencia educativa, ya que se planteó un trabajo con profesores que hubiesen podido ejercer la docencia, como mínimo a la largo de los últimos diez años, en contextos diferentes y, en consecuencia, contrastables. En segundo lugar, la voluntad de formarse ante los nuevos retos relacionados con el plurilingüismo y la interculturalidad. En tercer 
lugar, abastar las distintas etapas educativas, desde infantil (3 años) hasta secundaria (16 años).

A cada uno de los participantes se le pidió su colaboración en tres procesos de construcción de discurso, cada uno de los cuales presenta las características de un texto reflexivo:

- Discursos individuales : redacción del propio relato de vida lingüística.

- Discursos co-contruidos entre dos: participación en una entrevista, de unos 35 minutos de duración, con el investigador.

- Discursos construidos en grupo: colaboración en 4 debates con todos los participantes, de 2 horas aproximadamente cada uno.

11 La redacción del relato de vida lingüística se planteó de manera abierta. Debía tener una extensión máxima de dos páginas y tratar, por una parte, cuestiones relacionadas con el conocimiento y el uso de las lenguas y, por la otra, con sensaciones y reflexiones surgidas a parir de la experiencia de enseñar en contextos plurilingües.

La participación en la entrevista se planteó como «una conversación orientada», de manera que el entrevistado construía una narración a petición del investigador, con el propósito concreto y compartido de reflexionar acerca de su repertorio lingüístico. Las entrevistas se concibieron de esta manera para crear un espacio en el que el sujeto pudiese adquirir la condición de autoinformante de unos acontecimientos concretos $\mathrm{y}$, a la vez, del contexto social donde estos acontecimientos han ocurrido (Cambra, 2003; Palou, 2008). Las entrevistas se grabaron en audio y posteriormente se transcribieron para analizarlas ${ }^{3}$.

13 Se realizaron cuatro debates en grupo. En el primero de ellos se abordaron los temas más relevantes que habían aparecido en las entrevistas; queremos destacar que a nuestro entender el criterio de relevancia se relaciona con la cantidad y con la profundidad. Así, se apuntaron unas cuestiones que habían aparecido de manera repetida en las entrevistas y otras que eran muy significativas, aunque no tan recurrentes. En cada uno de los otros tres debates los maestros y profesores aportaron grabaciones que ellos mismos habían seleccionado de sus clases para comentarlas de manera conjunta; ellos las presentaban y el resto de participantes aportaban sus interpretaciones. En estas tres sesiones de autoconfrontación los investigadores actuaron como dinamizadores y conductores de la discusión, para favorecer un proceso cooperativo entre los participantes y crear un clima de confianza (Woods, 1996). Todos los debates se grabaron en audio y vídeo y se transcribieron para el análisis.

\section{Método de análisis de datos}

Para el análisis de los datos compartimos las aportaciones de los teóricos del discurso según las cuales es posible acercarse de manera cualitativa a la expresión singular de cada persona. Para comprenderla mejor, esta expresión debemos situarla en su contexto. Se trata de tomar la palabra como una fuente del análisis para llegar al significado y realizar una lectura en profundidad a través de varias relecturas y del contraste de las interpretaciones con el equipo de investigadores.

Los métodos de análisis que se adaptan mejor a las necesidades de nuestro estudio son las derivadas del análisis del discurso y en especial del discurso en interacción (KerbratOrecchioni, 2005) en sus tres dimensiones: interlocutiva, temática y enunciativa, ya que 
nos interesa analizar lo que dicen los participantes y cómo lo dicen. Tomando en consideración las tres dimensiones de análisis propuestas, así como el objetivo que perseguimos de profundizar en los CRS de los profesores sobre el plurilingüismo y su evolución, se siguió el proceso de análisis que explicitamos a continuación:

- Lectura en profundidad del texto. Se lee y relee el discurso, ya sea el texto escrito por el profesor, ya sea la transcripción de entrevistas orales o de debates en grupo, tantas veces como sea necesario para impregnarse de lo que se dice, teniendo en cuenta el modo y tomando notas o subrayando los aspectos que se creen más relevantes tal como van apareciendo. Se trata de sumergirse en lo que se dice, en el tono en que se expresa, para entender lo que quiere decir el que habla o escribe. De este primer paso se desprende una sensación general e intuitiva de los CRS de la persona estudiada y emergen hipótesis.

- Análisis de los textos orales y escritos, tanto monologados como creados en situación de diálogo, en sus tres dimensiones (Kerbrat-Orecchioni, 2005; Palou \& Fons, 2010):

La dimensión interlocutiva, pretende establecer el marco de la participación y atiende al tipo de discurso, a su organización, a la lengua elegida y a los cambios de código, así como la apertura y clausura del discurso.

17 La dimensión temática busca las palabras clave que se aglutinan alrededor de un tópico, sus contextos y su relación con otros elementos semánticos a partir de las cuales confeccionamos constelaciones semánticas. Se busca de manera especial la relación de las lenguas con en el eje temporal, o etapas de la vida, y su relación con el contexto. Se analiza el orden de aparición de las lenguas y su relación con el modo de aprenderlas; asimismo, se considera la relación de la experiencia personal con la profesional.

La dimensión enunciativa analiza: los marcadores personales, los indicadores de la posición de los hablantes, las autodefiniciones, el juego dialéctico entre identidad y alteridad (yo/ellos), la expresión de la posición espacio-temporal (aquí/allí, ahora/antes), los modos verbales y las perífrasis verbales de obligación, las formas de designación, los juicios y las valoraciones, las clasificaciones, categorizaciones y bipolarizaciones, las metáforas, el relato y la ejemplificación, las historias ilustradas con ejemplos, detalles y anécdotas con valor explicativo y argumentativo.

19 - Síntesis de los CRS, de las «tensiones» y de los contextos en los que han surgido. Es especialmente relevante indagar sobre las tensiones entendidas en el sentido de divergencias entre distintas fuerzas que se producen en el mismo discurso de los profesores como consecuencia de la narración de experiencias emocionalmente fuertes que han marcado un antes y un después, o como fruto de los entornos geográficos, sociales y políticos en los que se desarrolla cada individuo y de los contextos de aprendizaje de las lenguas. El estudio de las tensiones, que asociamos a los «hotspot» (Woods, 1996; Phipps \& Borg, 2009), se muestra relevante en este trabajo ya que permite proponer nuevos criterios para la formación de los profesores en contextos multiculturales y multilingües.

\section{Resultados del análisis de los datos}

Santi, en su relato de vida escrito y en la entrevista se declara como persona totalmente bilingüe. En los diferentes contextos discursivos (relato, entrevista, debates) cree necesario hacer referencia a sus orígenes familiares. Es consciente de ser un claro ejemplo de persona a la cual el contexto histórico y la voluntad personal le han llevado a cambiar 
su lengua habitual, ya que su lengua familiar era el castellano y actualmente utiliza siempre el catalán. En la cuarta sesión de los debates en grupo aparece el tema de las lenguas de los emigrantes de segunda generación y la constatación de la formación de guetos culturales y lingüísticos en barrios periféricos de diversas ciudades. Esta concentración repercute en las escuelas de la siguiente manera: los alumnos autóctonos tienden a agruparse en centros determinados, distintos a los que asisten los hijos de familias inmigrantes recién llegadas. Ante esta realidad Santi recuerda su experiencia personal :

jo:: bueno ho he viscut en:: primera persona | jo sóc fill d'aquestes generacions dels seixanta i pico que venien de:: de Granada en aquest | cas aquí per tant els meus pares són andalusos i jo sóc nascut aquí i:: el tema a casa meva sempre s'ha parlat castellà els meus pares no saben parlar català tot $i$ viure aquí fa més de quaranta anys $i^{\text {no? }}$ (...) jo ho veig així que és molt curiós perquè $\mid$ nyt $\mid$ a veure intentes com ¿no? a veure ets d'aquí és aquest que comentaves tu ¿no? el fet de:: o tu perquè t'has de sentir d'allà o d'aquí és cert que a casa hi ha aquesta llengua o aquesta cultura o tal però tu després també la pots transformar una mica ¿no? vull dir:: i:: $\mathrm{i}$ sí costa perquè segons el lloc o segons tu el tarannà o per on hagis volgut encaminar és difícil clar a mi els meus cosins |e| em qüestionen perquè jo he canviat la llengua de la família ¿no? ${ }^{4}$

También en la entrevista expresa:

(...) i:: bueno te n'adones que realment ets tu que hi has de posar de la teva part $\mathrm{i}$ anar-te introduint en aquests grupets d'amics i fer noves amistats parlant català (...)

21 Aunque concluye que es difícil, Santi parte de su ejemplo como testimonio de dos cuestiones: no es imposible romper con los guetos y es posible cambiar la lengua de uso habitual. Si analizamos su discurso observamos que empieza utilizando la primera persona para exponer los datos factuales (he vivido, soy hijo de, soy nacido) y pasa a usar la segunda persona del singular (intentas, debes sentirte, tu puedes) para exponer experiencias relacionadas con sus sentimientos y su voluntad. Interpretamos que usa el pronombre tú, que no deja de ser un yo encubierto, para minimizar su ejemplaridad o protagonismo y también como invitación al cambio de lengua habitual, ya que este cambio depende de la propia voluntad. De algún modo involucra a los demás en su propia experiencia, de manera empática y dando por bueno lo que formula en el discurso acerca de poder transformar la identidad lingüística y cultural recibida.

En un momento de la entrevista también aclara que él ha podido cambiar de lengua por voluntad y por la pasión que tiene por las lenguas. Relaciona este cambio con el salir de uno mismo y abrirse al mundo.

(...) per aquesta aquesta voluntat lingüística aquest aquest |mh::: no sé aquesta passió que jo tinc per les llengües/ doncs m'ha fet obrir la meva ment a nivell lingüístic |a::: cap a diferents perspectives i voler conèixer (.... ${ }^{6}$

23 Santi calla en muchos de los temas que aparecen en los debates. Por ejemplo, cuando se centran en las culturas o la inestabilidad emocional de algunos de los alumnos inmigrantes. En estos casos solo asiente o colabora con las opiniones de los demás, sin embargo, se muestra siempre dispuesto a intervenir para aportar testimonios de cambio de lengua, como el siguiente:

(...) aquest és romanès ha arribat aquest any $\mathrm{i}$ amb la mare continua parlant romanès però la mare ara té una nova parella que és d'aquí i llavors amb aquesta parella parla les dues:: llengües ¿no? i és una mica veure el procés d'ells com a:: nouvinguts i immersos amb un model de família diferent que van canviant i es van es van:: adaptant. ${ }^{7}$ 
Está claro que Santi tiene una sensibilidad especial hacia las situaciones en las que, por el motivo que sea, se produce un cambio de lengua. Apoya con su experiencia que este cambio es factible, aunque reconoce que es difícil y que precisa de voluntad.

Por otra parte, la relación entre lengua y conocimiento del mundo y sus culturas es algo presente en el discurso de Santi.

(...) Com més llengües entén i parla una persona, més facilitat per adquirir coneixements i més ric no només el seu pòsit lingüístic sinó també la seva formació i creixement personal.

En su relato de vida concreta y amplía la relación entre lengua y cultura.

(...) El que tinc clar és que una llengua no és només un mitjà de comunicació, sinó un instrument que porta implícita una gran càrrega de cultura pròpia de la comunitat i/o el lloc on aquesta es parla. ${ }^{9}$

Esta cuestión se relaciona también con su experiencia personal, puesto que fue en clase de francés donde conoció a su mujer. En la entrevista manifiesta:

(...) si no hagués tingut l'interès lingüístic d'anar a conèixer una altra llengua una altra:: cultura doncs mira igual no:: ens haguéssim trobat (S riu). ${ }^{10}$

2 Su experiencia como hablante bilingüe, añadida a la de profesor de lengua extranjera, le permite aproximarse al reconocimiento de distintos repertorios lingüísticos en diversas lenguas, aunque mantiene el conocimiento de cada una por separado.

(...) el fet $d$ 'haver començat a conèixer més llengües i parlar-les m'ha fet veure que:: doncs que puc ser igualment vàlid comunicant-me amb castellà que amb català que amb anglès que amb una altra i ell doncs (es refereix al seu germà) canvia de fet amb els seus fills també li passa o sigui com que es veu que no és una:: llengua que la té:: cent per cent:: dominada doncs en el moment de renyar-los en el moment de:: | mh::: no només de renyar sinó de situacions més de carinyo i així d'estimació canvia al castellà perquè li surt més fàcil en canvi jo amb la meva filla doncs ho faig tranquilllament en català. ${ }^{11}$

Aparece la metáfora de «dominar una lengua cien por cien» que interpretamos como reflejo de la idea extendida que saber una lengua es saberla como un nativo, aspecto que se confirma con el término «dominar». Aunque la palabra dominar se usa para expresar que se conoce algo en profundidad, refleja también que se tiene algo bajo control. Ello explicaría que en situaciones más emotivas, para reñir o para mostrar afectos, se produce a menudo un cambio de lengua. El cambio de una lengua a otra se valora más como una falta de dominio de la lengua en todos sus repertorios que como una característica propia de la competencia plurilingüe.

Santi interviene en uno de los debates, también, cuando se habla del conocimiento de una lengua relacionándolo con la capacidad de soñar en dicha lengua.

Santi: perquè a mi m'ha passat ¿no? estar a Anglaterra durant un temps i i un dia somiar en anglès ino? i dius |uil però dius és la llengua que estàs fent servir les vinti-quatre hores per tant

Maite: clar i a més a més és molt [d'esforç]

Santi:[va arribar a ser normal] però ella diu que no que tot i fer servir una llengua amb una persona ella continuava somiant amb la seva llengua com per tenir aquest d'allò de identitat o de poder:: és curiós. ${ }^{12}$

Interpretamos la posibilidad de soñar como expresión máxima de conocer la lengua como un nativo y con la idea subyacente de que cada lengua constituye un compartimento estanco. Esta representación mental se ratifica al final de la intervención con el calificativo «curioso» cuando se contrasta con la representación de otra docente. 
32 Su percepción del plurilingüismo en el aula se centra en la convivencia de alumnos de distintas etnias o comunidades. Santi manifiesta un cambio de percepción después de presentar ante el grupo de debate la actividad que realizó con los alumnos de cuarto grado, consistente en la escritura de las historia de vida lingüística:

(...) jo pensava que només parlarien\} el xinès el romanès el d'allò i no els altres han volgut dir molt la seva dir de la seva història una mica | tal com ho han viscut. ${ }^{13}$

33 Es interesante esta ampliación del conocimiento de lenguas por parte de los otros constatada por Santi. Los «otros» los que no son de fuera, los de aquí de siempre son ahora más semejantes al resto de la clase, pues también tiene su historia de vida lingüística y podemos reconocer, pues, el plurilingüismo de cada individuo como particular y distinto.

34 A lo largo de su relato de vida lingüística Santi valora de manera 'positiva el papel de la escuela para aprender lenguas:

(...) Les coses van canviar quan vaig començar l'escola l'any 1978. En aquells temps el català tot just s'estava introduint a poc a poc en el món educatiu.

Vaig tenir la gran sort d'anar-me familiaritzant amb la llengua de la terra amb certa facilitat (...). ${ }^{14}$

y relaciona siempre el aprendizaje de las lenguas que conoce con el estudio y las situaciones académicas:

(...) He estudiat anglès, francès, alemany, italià i una miqueta d'àrab. Les quatre primeres les entenc tant a nivell oral com escrit $i$ les faig servir quan és necessari. L'àrab tot just l'estic començant (....). ${ }^{15}$

Al mismo tiempo critica profundamente los métodos que no potencian la expresión oral, ya que no permiten la comunicación como muestra su experiencia; apunta, también, la importancia del enfoque comunicativo para aprender lenguas. Este enfoque lo ha aprendido y asimilado a lo largo de su formación como maestro:

(...) és el que intento ¿no? poder fer que:: el que jo he viscut sigui equiparable en els meus alumnes i sobretot fugir molt del tema escrit en els nivells inicials $\mathrm{i}::$ i i i poder fer això un ús funcional de la llengua. ${ }^{16}$

(...) gràcies a la meva formació com a mestre, he descobert que la competència comunicativa i d'ús d'una llengua és quelcom molt important a l'hora d'aprendrela. ${ }^{17}$

El aspecto comunicativo de las lenguas aparece constantemente a lo largo de sus discursos y tomando la comunicación como argumento expone, también, cómo ha cambiado a lo largo de su experiencia docente el uso de otras lenguas, distintas de lengua meta, en sus clases.

(...) els nens han d'aprendre les llengües en un context de situacions que s'apropin a les que viuen en la seva vida diària, donant importància a la comunicació..$^{18}$

(...) l'important és la comunicació i que mica en mica anem posant tots els paràmetres lingüístics ¿no ${ }^{19}$

(...) dins de l'aula vull dir que és facilitar una mica que la comunicació sigui efectiva i que puguis e:: fer servir el que toca però:: |nyt| amb amb de la manera que que creus que els nens aprofitaran al màxim. ${ }^{20}$

Sin embargo, cuando trata de ayudar a un recién llegado, la valoración del uso de una lengua comprensible por el alumno para aprender la lengua meta es la siguiente

(...) si hi ha moments que no estem a dins de l'aula (se refiere al aula habitual dónde la lengua vehicular es el catalán) i veig que amb ell necessita doncs que la comunicació sigui perquè:: em diu:: ¿can I go to the toilet? I jo li dic |jah!| què dius ¿que vols anar al lavabo? Com que per exemple en aquell moment no estem a l'aula jo també l'ajudo com a mestre de llengües a que ell pugui fer el seu:: propi procés. ${ }^{21}$ 
ee plantea como una concesión el hecho de comunicarse en inglés con un alumno recién llegado, pues solamente lo hace si está fuera del aula ya que dentro del aula en que la lengua vehicular no es el inglés eso no estaría permitido, ya que se supone que debería hablarse la lengua meta.

\section{Conclusiones} el debate, provoca cambios de perspectiva se construyen nuevos modelos praxiológicos para la enseñanza de lenguas. Así, el modelo representado por la exigencia de hablar únicamente la lengua meta en las clases, está cediendo espacio en favor de un modelo alternativo según el cual puede ser un elemento facilitador el hecho de hablar otras lenguas comprensibles por los alumnos. Esta alternancia de lenguas puede favorecer la comprensión de algunos aspectos de la lengua meta.

Se reconfigura el modelo de aula plurilingüe. No se trata solo de confluir en una misma aula sujetos de distintas etnias y culturas, sino de apreciar y valorar los caminos trazados por cada individuo. Cado uno de ellos es exponente de unas lenguas aprendidas en distinto grado a lo largo de la vida.

La valoración positiva del enfoque comunicativo de la enseñanza de lenguas que aparece en nuestro análisis no es nada nuevo sin embargo, queremos destacar la revalorización que se hace de dicho enfoque cuando se explicita la experiencia negativa y frustrante que han supuesto los modelos basados en la enseñanza de la gramática y la memorización a los que han sido expuestos en su experiencia como aprendices. Nuestro informante concibe el enfoque comunicativo de manera aditiva, se prioriza el uso de la lengua y se añade luego la reflexión lingüística. Se percibe, además, la idealización sobre lo que representa saber una lengua. Emerge una vez más la creencia de que conocer una lengua es dominarla como un nativo.

\section{Criterios para un dispositivo de formación}

Del estudio de los CRS, surgen las siguientes consideraciones que pueden servir de criterios para afrontar un dispositivo de formación en educación plurilingüe.

En primer lugar, la formación para desarrollar una educación plurilingüe debería contemplar una amplia base de conocimientos teóricos. La noción de plurilingüismo 
requiere ser explorada y bien delimitada junto a otros conceptos como ideologías lingüísticas, contacto de lenguas, substitución lingüística, identidades, o las relaciones entre lenguas, culturas y territorios, derivados del campo de la sociolingüística y de la psicolingüística.

En segundo lugar sería necesario explicitar la distinción entre una visión monolingüe del plurilingüismo y una visión plurilingüe del mismo, siguiendo las orientaciones del Consejo de Europa.

Una tercera propuesta es promover el contraste del propio relato de vida lingüística con el de los alumnos, ya que puede ser una buena estrategia para profundizar en la gran diversidad de situaciones plurilingües y la manera de situarse en ellas. La mitificación del profesor nativo debe ser contrastada con las posibilidades que abre la reflexión sobre la experiencia de aprender lenguas y apostar por un reelaboración de los repertorios didácticos que permitan el desarrollo de la competencia plurilingüe.

En cuarto lugar proponemos una actualización de los recursos metodológicos en el sentido de explorar todos los recursos comunicativos posibles y de transitar de un lenguaje a otro, así como de una lengua a otra, reelaborando los modelos basados en el uso de la lengua meta como único medio de comunicación en el aula.

Finalmente, proponemos una formación que tome en consideración una práctica reflexiva que ayude a localizar los conflictos emergentes y sepa analizar actuaciones posibles. Los textos reflexivos, la autoconfrontación, y los debates en grupo se muestran como potentes mediadores para crear un discurso que permita analizar las actuaciones de manera crítica y plantear propuestas colectivas que faciliten la convivencia en un entorno con diversidad de lenguas y culturas.

\section{BIBLIOGRAFÍA}

Borg, S. (2003). Teacher cognition in language teaching: a review of research on what language teachers think, know, believe, and do. In Language Teaching, no36 (2), pp.81-109.

Borg, S. (2006). Teacher cognition and language education: Research and practice. London: Continuum. Calderhead, J. (1996). Teachers' beliefs and knowledge. In Berliner, D.-C. \& Calfee, R.-C. (Eds.), Handbook of Educational Psychology. Nueva York: MacMillan.

Cambra, M. \& Palou, J. (2007). Creencias, representaciones y saberes de los profesores de lenguas en las nuevas situaciones plurilingües escolares de Cataluña. In Cultura \& Educación, no19 (2), pp.149-163.

Cambra, M. (2003). Une approche ethnographique de la classe de langue. París : Didier.

Cambra, M., Ballesteros, C., Palou, J., Civera, I., Riera, M., Perera, J. \& Llobera, M. (2000). Creencias y saberes de los profesores en torno a la enseñanza de la lengua oral. In Cultura \& Educación, n¹2 (1-2), pp.25-40. 
Clarà, M. \& Mauri, T. (2010). El conocimiento práctico. Cuatro conceptualizaciones constructivistas de las relaciones entre conocimiento teórico y práctica educativa. In Infancia y Aprendizaje, $\mathrm{n}$ 33 (2), pp.131-141.

Clark, C.-M. \& Peterson, P. (1986). Teachers' thought process. In Wittrock, M. C. (Ed.), Handbook of research on teaching. Nueva York: MacMillan.

Causa, M. (2012). Formation initiale et profils d'enseignants de langues : Enjeux et questionnements. Bruxelles : De Boeck Supérieur.

Freeman, D. (1996). Redefining the relationship between research and what teachers know. In Bailey, K.-M. \& Nunan, D. (Eds.), Voices from the language classroom (pp.88-115). Cambridge: Cambridge University Press.

Kerbrat-Orecchioni C. (2005). Le discours en interaction. Paris : A. Colin, 2005.

Meijer, P., Verloop, N. \& Beijard, D. (1999). Exploring language teacher's practical knowledge about teaching Reading comprehension. In Teaching and Teacher Education nำ15, pp. 59-84.

Moore, D. (2001) (Ed.). Les représentations des langues et de leur apprentissage. Itinéraires théoriques et trajets méthodologiques. Paris : Didier, 2001.

Palou, J. \& Fons, M. (2008). Evolución de las representaciones de los profesores sobre el plurilingüismo en procesos de formación en el centro educativo. In Barrio, J.-L. (Ed.), El proceso de enseñar lenguas. Investigaciones en didáctica de la lengua (pp. 295-328). Madri: La Muralla.

Palou, J. (2008). L'ensenyament i l'aprenentatge del català com a primera llengua a l'escola. Creences $i$ actuacions dels mestres amb relació a les activitats de llengua oral a l'etapa primària. Barcelona: Institut d'Estudis Catalans.

Palou, J. \& Fons, M. (2010). Metacognició i relats de vida lingüística en els processos de formació del professorat. Anàlisi del relat d'una alumna. In Multilingüisme i pràctica educativa (pp. 255-260). Girona: Universitat de Girona.

Phipps, S. \& Borg, S. (2009). Exploring tensions between teachers' grammar teaching beliefs and practices. In System, no37 (3), pp. 380-390.

Pozo, J.-I., Scheuer, N., Mateos, M., Pérez-Echevarría, M.-P., Martín, E. \& Cruz, M. (2006). Nuevas formas de pensar el aprendizaje y la enseñanza. Concepciones de profesores y alumnos. Barcelona: Graó.

Rodrigo, M.-J. (1997). Del escenario sociocultural al constructivismo episódico: un viaje al conocimiento escolar de la mano de las teorías implícitas. In Rodrigo, M.-J. \& Arnay, J. (Eds.), La construcción del conocimiento escolar (pp. 177-191). Barcelona : Paidós.

Schön, D. (1987). Educating the reflective practitioner. San Francisco: Jossey-Bass.

Shavelson, R.-J. \& Stern P. (1981). Research on teachers' pedagogical thoughts, judgments, decisions and behavior. In Review of Educational Research, nํ51, pp.455-498.

Woods, D. (1996). Teacher Cognition in Language Teaching. Beliefs, Decision-Making and Classroom Practice. Cambridge : Cambridge University Press.

\section{NOTAS}

1. Referencia del proyecto (I+D): ECRELEN-EDU2010-21056. Financiado por el Ministerio de Ciencia e Innovación

2. Para más información: http://www.ub.edu/plural/ 
3. El Código de transcripción utilizado es el siguiente: [texto afectado]: encabalgamiento; |: pausa corta (1-3"); ||: pausa mediana (+ de 3"); /: entonación ascendente; ¿?: entonación interrogativa; s::i o si:: : alargamiento de sonido; $\mathrm{p}$ - : corte abrupto; (F): forte o más volumen de voz; (( )): hecho no verbal; cursiva: en otro idioma; X: palabra no inteligible; XX: enunciado no inteligible; (...) fragmento no transcrito

4. Incluimos las traducciones sin indicar los elementos seguidos en la versión original para la transcripción."Yo, bueno lo he vivido en primera persona, yo soy hijo de estas generaciones de los sesenta y pico que venían de Granada en este caso aquí, por tanto mis padres son andaluces y yo soy nacido aquí y el tema en mi casa siempre se ha hablado castellano, mis padres no saben hablar catalán a pesar de vivir aquí hace más de cuarenta años ¿no?. Yo lo veo así, que es muy curioso porque, a ver intentas como ¿no? a ver eres de aquí es ese que comentabas tú ¿no? el hecho de o tú porque has de sentir de allí o de aquí es cierto que en casa hay esa lengua o esta cultura o tal pero tú después también la puedes transformar un poco ¿no? quiero decir y sí cuesta porque según el lugar o según tú el talante o por donde hayas querido encaminar es difícil claro a mí mis primos me cuestionan porque yo he cambiado la lengua de la familia ¿no?

5. Y bueno te das cuenta que realmente eres tú que tienes que poner de tu parte e irte introduciendo en estos grupitos de amigos y hacer nuevas amistades hablando catalán

6. Por esta voluntad lingüística este no sé esta pasión que tengo por las lenguas pues me ha hecho abrir mi mente a nivel lingüístico hacia diferentes perspectivas y querer conocer

7. Este es rumano ha llegado este año y con la madre sigue hablando rumano, pero la madre ahora tiene una nueva pareja que es de aquí y entonces con esta pareja habla las dos lenguas ¿no? y es un poco ver el proceso de ellos como recién llegados e inmersos con un modelo de familia diferente que van cambiando y se van adaptando

8. Cuanto más lenguas entiende y habla una persona, más facilidad para adquirir conocimientos y más rico no solo su poso lingüístico sino también su formación y crecimiento personal.

9. Lo que tengo claro es que una lengua no es solo un medio de comunicación, sino un instrumento que lleva implícita una gran carga de cultura propia de la comunidad y o el lugar donde ésta se habla.

10. Si no hubiera tenido el interés lingüístico de ir a conocer otra lengua otra cultura pues mira igual no nos hubiéramos encontrado (S ríe).

11. El hecho de haber empezado a conocer más lenguas y hablarlas me ha hecho ver que, pues que puedo ser igualmente válido comunicándome en castellano que en catalán que en inglés que con otra y él pues (se refiere a su hermano) cambia de hecho con sus hijos también le pasa o sea como se ve que no es una lengua que la tiene cien por cien dominada, pues en el momento de regañarlos en el momento de no solo de reñir sino de situaciones más cariño y así de estimación cambia al castellano porque le sale más fácil, en cambio yo con mi hija pues lo hago tranquilamente en catalán.

12. Santi: Porque a mí me ha pasado ¿no? estar en Inglaterra durante un tiempo y un día soñar en inglés ¿no? y dices pero dices es la lengua que estás usando las veintidós cuatro horas por lo tanto.Maite: Claro y además es mucho esfuerzo.Santi: Llegó a ser normal, pero ella dice que no, que a pesar de usar una lengua con una persona ella continuaba soñando con su lengua como para tener este de lo identidad o de poder, es curioso.

13. Yo pensaba que solo hablarían el chino, el rumano, el de aquello, y no los otros han querido decir mucho, su decir de su historia un poco tal como lo han vivido.

14. Las cosas cambiaron cuando empecé la escuela en 1978. En aquellos tiempos el catalán apenas se estaba introduciendo poco a poco en el mundo educativo. Tuve la gran suerte de irme familiarizando con la lengua de la tierra con cierta facilidad.

15. He estudiado inglés, francés, alemán, italiano y algo de árabe. Las cuatro primeras las entiendo tanto a nivel oral como escrito y las uso cuando es necesario. El árabe apenas la estoy empezando. 
16. Es lo que intento ¿no? poder hacer que lo que yo he vivido sea equiparable en mis alumnos y sobre todo huir mucho del tema escrito en los niveles iniciales y poder hacer esto un uso funcional de la lengua.

17. Gracias a mi formación como maestro he descubierto que la competencia comunicativa y de uso de una lengua es algo muy importante a la hora de aprenderla.

18. Los niños deben aprender las lenguas en un contexto de situaciones que se acerquen a las que viven en su vida diaria, dando importancia a la comunicación.

19. Lo importante es la comunicación y que poco a poco vamos poniendo todos los parámetros lingüísticos ¿no?

20. Dentro del aula quiero decir que es facilitar un poco que la comunicación sea efectiva y que puedas usar lo que toca pero de la manera que crees que los niños aprovecharán al máximo.

21. Si hay momentos en que no estamos dentro del aula (se refiere al aula habitual dónde la lengua vehicular es el catalán) y veo que con él necesita pues que la comunicación sea porque me dice:¿can I go to the toilet? Y yo le digo: ¡ah! Qué dices ¿que quieres ir al baño? Como por ejemplo en aquel momento no estamos en el aula yo también le ayudo como maestro de lenguas que él pueda hacer su propio proceso.

\section{RESÚMENES}

Esta investigación expone un proceso de formación de docentes que trabajan en entornos multiculturales y multilingües. Dicho proceso se basa en la reflexividad dialógica, propiciada mediante la creación de espacios discursivos generados por historias de vida lingüística, entrevistas, grupos de discusión y autoconfrontaciones. Los resultados indican que las representaciones emergen cuando se ponen en marcha procesos de interpretación de la acción y del discurso sobre la acción.

Cette recherche expose un processus de formation où les enseignants participants travaillent dans des environnements multiculturels et multilingues. Ce processus est basé sur la réflexivité dialogique, créant des espaces discursifs générés par des histoires de vie linguistique, interviews, groupes de discussion et autoconfrontations. Les résultats de cette recherche montrent que les représentations émergent lorsque l'on met en place des processus d'interprétation dans l'action et dans le discours sur l'action.

\section{ÍNDICE}

Palabras claves: autoconfrontación, competencia plurilingüe, formación, relatos de vida lingüística

Mots-clés: autoconfrontacion, compétence plurilingue., formation, histoires de vie linguistique 


\section{AUTORES}

\section{MONTSERRAT FONS}

Profesora titular del departamento de Didáctica de la Lengua i la Literatura, Universitat de Barcelona

\section{JULI PALOU}

Profesor titular del departamento de Didáctica de la Lengua i la Literatura, Grupo de investigación PLURAL, Universitat de Barcelona 